$(0)^{3}(B)$

1

\section{$T, 11810$ \\ (1)}

UCID $=-19907$

DEOA 001660

\author{
A STATUS REPORT EOR DATA FILES AND \\ MONTE CARLO TRANSPORT CODES \\ MAINTAINED BY THE PHYSICAL DATA GROIJP OF LLNL
}

Robert J. Howerton

Oetober 18, 1983

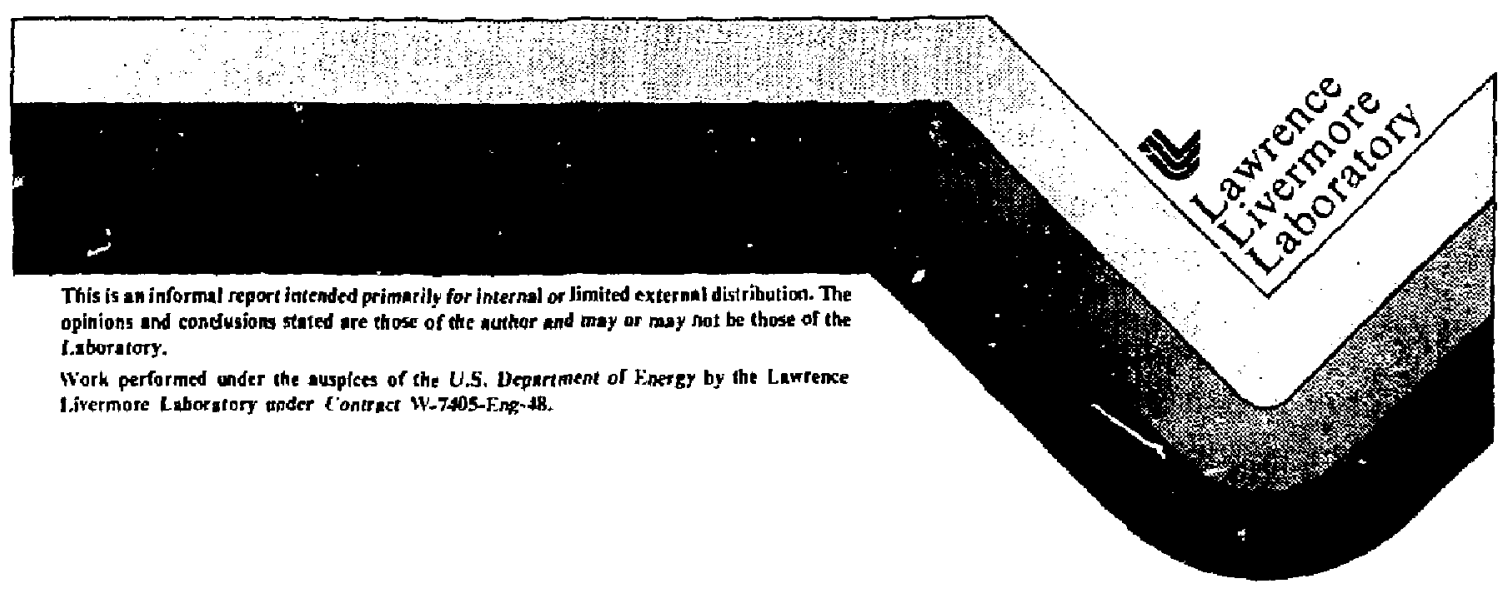




\title{
A STATUS REPORT FOR DATA FILES AND MON'TF CARLO TRANSPORT CODES MAINTAINED BY THE PHYSICAL DATA GROUP OF LLNL
}

\author{
Robert J. Howerton \\ Lawrence Livermore National Laboratory \\ Livermore, California 94550
}

The Physical Data Group of the Theoretical Physics Division of LLNL has developed and maintains :ieveral basic data files, several Monte Carlo transport codes, and the requisite processing codes that convert the basic data to the form required bv our own transport codes and by other laboratory transport and burn codes.

The data files (lihraries) that we maintain are listed helow together with a few comments about each.

- ENUL (Evaluated Neutron Deta Library)

This is the file for neutron induced reaction data and contains cross sections, anguler ano energv distribucions for all secondary particles, secondary particle multiplicities for neutrons and gammas, average energies for all secondary particles and residuals. In short, it contains all appropriate data associated with neutron-indueed reactions for 98 isotopes or elemental mixtures of isotopes plus a lumped fission product. ENDL is documented in Volume 4, Rev. 1; Volume 15, Parts A through E of UCRL 50400 . ENDL is now a relatively stable data file with modifications to existing data usually made only as new experimental data come to hand or when we are requested to check the validity of some part of the data and find that an improvement should be made.

- ACTL. (Neutron-Induced Activation Library)

This file contains eross sections for the production of radiogctive residual ntlclei from neutron-induced reactions. There are currently 1822 individual cross section sets in ACTI. About $20 \%$ of the reactions have a stable nucleus for the residual. These are includer for two reasons. First, thev provide data for those applications in which the depletion of a population of a particular nuclear specie is important. Second, for completeness in the sense of including all reactions of a particular type (e.g. $n, r ; n, p$; $n, \alpha ; n, 2 n)$ that have been requested. An early version of ACTL is documented in Volume 
18 of UCRL 50400. In contrast to the ENDL file, ACTL is being continuously developed within the limitations of avallable effort that can be allocated to that function. 'lo update existing reaction dnta and extend the file to a satisfactory state of completeness would require the full-time effort of one person on a continuing basis. While a fill-time effort of one person for two years would oring ACTL to a state of relative completeness, it would require a continuing effort to improve and devolop the empirical and theoretical methods that must be used to obtain eross sections where they cannot be measured because of the unavailability of target materinls.

- ECPL (Evaluated Charged Particle-Induced Library)

This file contains data for reactions induced by the five light charged particles ( $P$, $\left.\mathrm{d}, \mathrm{t},{ }^{\mathrm{a}} \mathrm{He},{ }^{4} \mathrm{He}\right)$ for light targets $(\mathrm{Z} \leq 8)$. In addition to the usual reaction properties suchas cross sections, angular/energy distributions, etc., temperature (noppler) broadened ross sections, energy loss cross sectinns, Maxwell-averaged regetion rates, Maxwell-averaged average energy distributions for perticles and residuals, amd energy distributions faom thermal equilibrium reactions are incluried. While the ECPl, file has existed in one form or another for twenty or so years, it is onlv within the past few years that the extension from cross sections and haxuell-averared peretion rates has occurred. Th bring it to a maintenance level in the sense of including all reactions for all charged particles for all targets with $\lambda \leq 8$ will require consirlerable work. He are just now diseussing a joint effort with the T-2 group at IANL that hopefully will expedite the review of existing data in ECPL and fleshing it out to inciude all the necessary reactions. likewise a continuation of a long-standine collaboration with $A$. !. Smith's group at ANL will likelv yield new measurements (bv ANL) of important chargedparticle induced reactions that are needed for ECPI. Parts of the ECPI. file are documented in Volumes 15, Part F; and 21, Part A of UCRL 50400.

- EGDL (Evaluated Gamma Data Library)

This lile contains cross sections, etc. for photons with energies from $10 n \mathrm{eV}$ to $100 \mathrm{WeV}$ intergcting with cold ions of the elements from $z=1$ to $Z=98$. The reactions ineluded are coherent scattering, jncoherent scattering, photon-electric, and pair production. The EGDL file is doeumented in Volume 6 Revision 3 of UCRL $5040 n$.

- ENSL (Evaluated Nuclear Structure Librarỵ)

This file contains the nuclenr structure data that were published in the Seventh Edition of the Table of Isotopes. The level schemes in ENSL, were derived from the 
decav data of the Table of Isotopes. Another more extensive file (CDRL) contains the level schemes obtained from particle-induced reactions merged into the ENSL file. Both FNSL and CDRL are documented in Volume 23 of UCRL 5040n.

- GAMTOT83 is a file of photon energies and multiplicities associated with the time-rlependent decay of radio-active isotopes and with thermal neutron capture (Drompt photons). This file is for use with the GAMIDEN code and is documented in Volume 22, Revision 2 of UCR L 50400.

The Monte Carlo transport codes that we have developed and maintain are:

- Tart is a data dependent Monte Carlo neutron and/or photon transport cade. It uses cross sections as histograms (e.g. 175 values from $1.3 \times 10^{-9}$ to $20 \mathrm{meV}$ for neutrons) but follows particles on a continucus energy basis. For transport problems in which extreme fluctuations of cross sections (resonances) are not very important TART is the code of choice. For prob'ens that are sensitive to resonence regions the code ALICF (see below) which is based on the multi-band method is the code of choice. TART is a CRAY-I code. Its predecessor and CDC 7600 equivalent was the TARTNP code that is doeumenter in UCRL 50400 Volume 14 . The $m_{n}$ shods deseribed there are those used in TART.

- ALICE is a Monte-Cerlo multi-band method neutron and/or photon transport code. It is, in essence, the TART code with the multi-band method and a cepability for scattering in a temperature dependent medium added. This code provides a tool for transport calculations where the materials and neutron energv range of importance in the problem are characterized by resonance structure in the cross sections and/or a high temperature environment.

Other Physical Data Group aetivities are all intimately related to the data files and code development functions deseribed above. For example, an extensive file of experimental neutron-induced data (ECSIL) is maintained as the basic source of experimentat deta for ENDL and ACTL. Likewise, a family of codes is subsumed under a controller (OMEGA). This family of codes provides the means for updating and otherwise manipulating the data in ENDL, ACTL, EGDL, and ECPL. This includes providing the standard data files used by the LLNL transport and burn codes. 


\section{DISCLAIMER}

This seport way prepared as an account of wot sponsored by an agency of the United Siates GovernmenL. Neither the United States Gowernment nor any agency therenl, nor any of their employees, makes any wartanty, express of implied, or assumes any iegal liability or responsibility for the accuracy, completeness, or usefulness of any information, spparatus, produch or process diselosed, or represents that its use would not infringe privately owned rights. Feftrence herein to any specific commercial produce, process, or service by icade name, trademerk. manufacturer, or otherwise does not necessarily constitute or irnply its endorsement, rocommendation, or favoring by the United States Government of any agency thereof. The views and opinions of $p$ thors expressed herein do not necessarily state or reflect those of the United States Guvernment or any agency thereof. 